\title{
Potential of Wind and Solar Electricity Generation in Bangladesh
}

\author{
Sanjoy Kumar Nandi, ${ }^{1}$ Mohammad Nasirul Hoque, ${ }^{1}$ \\ Himangshu Ranjan Ghosh, ${ }^{2}$ and Swapan Kumar Roy ${ }^{3}$ \\ ${ }^{1}$ Department of Physics, University of Chittagong, Chittagong 4331, Bangladesh \\ ${ }^{2}$ Renewable Energy Research Centre, University of Dhaka, Dhaka 1000, Bangladesh \\ ${ }^{3}$ Department of Physics, Chittagong University of Engineering and Technology, Chittagnong 4349, Bangladesh
}

Correspondence should be addressed to Sanjoy Kumar Nandi, skumarnandi@yahoo.com

Received 29 October 2011; Accepted 11 December 2011

Academic Editors: C. Cristofari and A. Hasan

Copyright (C) 2012 Sanjoy Kumar Nandi et al. This is an open access article distributed under the Creative Commons Attribution License, which permits unrestricted use, distribution, and reproduction in any medium, provided the original work is properly cited.

Wind and solar energies are the alternative energy sources that can be used to supplement the conventional energy sources particularly in Bangladesh. In this work, the aim is to assess the current wind and solar energy potential in Bangladesh. The wind data for the five stations obtained from Local Government Engineering Department have been assessed, but only two of them seem to be eligible for energy production. Annual average, monthly average, and hourly average wind speeds and wind power densities were calculated from the wind data. The Weibull distribution parameters ( $\mathrm{c}$ and $\mathrm{k}$ ), the dominant wind directions, and the frequency distributions were also determined. Experimentally measured solar radiation data are not available over Bangladesh. Measured climatological data such as cloud cover and sunshine duration data of Bangladesh Meteorological Department from 1992 to 2001 used for the estimation of global solar radiation as they are correlated. Technoeconomic feasibility analysis is done for $100 \mathrm{~kW}$ grid connected wind and solar photovoltaic (PV) systems. Renewable-energy-based system will bring more environmental benefits than conventional power in terms of human health, reduction of air pollution, and decrease of noise, and so forth. However, in the above estimation, these were not considered.

\section{Introduction}

The growth of the world's human population has created several problems. One of them is global warming caused by the abundance of $\mathrm{CO}_{2}$ in the atmosphere. Many of these gases are produced from power plants burning fossil fuel all over the world. Electricity has a direct cost associated with it and the global price of electricity has increased steadily with increasing fuel price during the last decades. In some parts of the world there is still no electricity available or it is unreliable. Energy supply is a major problem for all classes in Bangladesh. The energy consumption rate is $208 \mathrm{kWh} /$ capita, which is the lowest in the world [1]. Electric generating capacity in 2010 was 5823 MGW, of which $96.05 \%$ was thermal, and the remainder hydroelectric, at 18 power stations $[2,3]$. The electricity infrastructure is old and badly maintained, breaks down frequently, and is inadequate to meet the demand. Power cuts are frequent; many areas are only supplied for a few hours a day. Some areas have no power for days at a time when a local generator fails. The green sources of energy include solar, photovoltaic, solar thermal, wind biomass, and hydro- and geothermal.Thus, it may be strategically important to check the possibility that a part of the energy needs of Bangladesh can be economically covered from renewable energy sources and mainly wind and solar energy. Anticipated increases in electricity rates, in tandem with potential future tax relief and government incentives for self-reliance using solar and wind power, however, will likely make "homemade" energy and the industrial sector an attractive practical and financial option in the near future. For proper economical analysis, accurate knowledge of the availability and variability of solar radiation intensity is essential. The measured solar radiation data are not available in Bangladesh. It was found that wind speeds in the coastal belt of Bangladesh were the only ones which showed promise. The assessment of the suitable regions for wind energy utilization and the estimation of the expected power production of wind turbines are a prerequisite for efficient wind turbines sitting under economical, social, and environmental constraints. 
TABLe 1: Measured wind speed at different heights and places in the coastal areas [4].

\begin{tabular}{|c|c|c|c|c|}
\hline Organization & Location & $\begin{array}{c}\text { Anemometer } \\
\text { height }(\mathrm{m})\end{array}$ & $\begin{array}{c}\text { Average } \\
\text { speed }(\mathrm{m} / \mathrm{s})\end{array}$ & $\begin{array}{c}\text { Measuring } \\
\text { period }\end{array}$ \\
\hline \multirow{7}{*}{ BCAS } & Kuakata & 25 & 4.5 & \multirow{7}{*}{ 09/96-08/97 } \\
\hline & Charfassion & 25 & 4.0 & \\
\hline & Noakhali & 25 & 2.9 & \\
\hline & Chittagong & 25 & 3.8 & \\
\hline & Kutubdia & 25 & 4.4 & \\
\hline & Cox's Bazar & 25 & 3.2 & \\
\hline & Teknaf & 25 & 2.8 & \\
\hline \multirow{2}{*}{ BCSIR } & Teknaf & 10 & 3.5 & \multirow{2}{*}{$01 / 01-04 / 02$} \\
\hline & Sant Martin & 30 & 4.7 & \\
\hline \multirow{3}{*}{ GTZ } & Feni & 20 & 4.0 & \multirow{3}{*}{ 06/96-05/97 } \\
\hline & Anwara & 20 & 4.4 & \\
\hline & Teknaf & 20 & 4.3 & \\
\hline
\end{tabular}

The estimation of the wind turbines potential is generally related to a very long meteorological study of the measures of the wind speed. Most of the previous wind speed data in Bangladesh available from the Bangladesh Meteorological Department (BMD). Meteorological stations measure winds at lower height and it has been found that BMD data gives low values due to the obstacle effect by trees and buildings close to the met stations [4]. However, normal hub-heights of modern wind turbines range from 20 to $40 \mathrm{~m}$. Thus, using meteorological data and designing wind energy conversion system is not significant. In 1996-97 under the WEST project Bangladesh Centre for Advanced Studies (BCAS) with the support of Local Government Engineering Department (LGED) measured wind speed and direction at $25 \mathrm{~m}$ height for seven locations near the seacoast, GTZ (a German Organization) also measured wind speeds for another three coastal locations at a height of $20 \mathrm{~m}$ and Bangladesh Council for Scientific and Industrial Research (BCSIR) measured wind speed for Dhaka, Teknaf, and Saint Martin locations from 1999-2001 [4]. For the wind energy assessment study in the coastal areas, data have been collected by different organizations and Table 1 shows the status of the collected data.

Solar photovoltaic technology is being used commonly to generate electricity for standalone power system. Solar radiation can be measured from meteorological parameters, such as cloud cover, sunshine duration, and temperature. Bangladesh Meteorological Department (BMD) collects sunshine duration data from all BMD stations sunshine recorders. Some locations' data may not be of good quality because of the placement of the sunshine recorder in the ground level, for the shading or for the unsatisfactory alignment of burning with the central line. Hence, predicted global radiation using these data will give large discrepancy with the actual values. Cloud cover is a direct indicator of sunshine duration and they are correlated. An increase in cloud cover shows a decrease in sunshine duration and vice versa.

In this study, the set of wind speed data measured by Sustainable Rural Energy (SRE) of Local Government Engineering Department (LGED) for Kutubdia, Sitakunda, Khagrachari, Chittagong University of Engineering and
Technology (CUET) and Kuakata from June 2005 to December 2006, was used for analysis of wind resource assessment. For estimation of global solar radiation from sunshine duration and cloud cover, we have collected sunshine duration and cloud cover data for 31 stations of Bangladesh Meteorological Department (BMD) for 1981-2001. Both organizations have been using the Campbell-Stokes sunshine recorders and have been measuring cloud cover by eye estimation in Octa. BMD was using the original CampbellStokes sunshine duration measurement cards since 1991, after that they are using locally made cards with different sensitivity than the original ones. To avoid unexpected error due to card change, studies have been done for 19922001 period. The long-term wind flow of Islands and the southern coastal belt of the country indicate that the average wind speed remains between 3 and $4.5 \mathrm{~m} / \mathrm{s}$ for the months of March-September and $1.7-2.3 \mathrm{~m} / \mathrm{s}$ for the remaining period of the year [4]. This indicates there is a good potential in islands and coastal areas for the application electricity generation from wind. But during the summer and monsoon seasons (March to October), there can be very low-pressure areas, and storm wind speeds of 200$300 \mathrm{~km} / \mathrm{h}$ can be expected. Wind turbines should be strong enough to withstand these high wind speeds [4]. The longterm average sunshine data indicate that the period of bright (i.e., more than $200 \mathrm{~W} / \mathrm{m}^{2}$ intensity) sunshine hours in the coastal region of Bangladesh vary from 3 to $11 \mathrm{~h}$ daily and

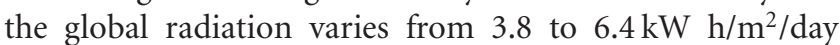
[5]. These data indicate that there are good prospects for solar, thermal and photovoltaic application in Bangladesh. So, densely populated tropical country like Bangladesh could be electrified by wind/PV grid system using the inexhaustible and pollution free solar and wind sources energy without using any novel technologies. Compensation of electricity shortage and reduction $\mathrm{CO}_{2}$ emission would be done by introducing wind and solar energy sources for electricity generation in mass scale. In this paper, techno-economic feasibility analyses are carried out for $100 \mathrm{~kW}$ wind and PV grid systems. To find the optimum size of inverter and for technical analysis, simulation software Renewable Energy Technologies screen (RETScreen) is used [6]. 


\section{Wind Resource Assessment}

Wind energy varies with year, season, and time of day, elevation above ground, and form of terrain. Proper position of turbine, in windy sites, away from large obstructions, improves wind turbines performance. Usually, the twoparameter Weibull probability density function is used to represent wind speed distributions [7]. Weibull probability distribution is used to determine parameters of the wind speeds. The Weibull distribution is a mathematical expression, which provides a good approximation to many measured wind speed distributions. The Weibull distribution is therefore frequently used to characterize a site. Such a distribution is described by two parameters: the Weibull "scale," parameter which is closely related to the mean wind speed, and the "shape" parameter, which is a measurement of the width of the distribution. This approach is useful since it allows both the wind speed and its distribution to be described in a concise fashion.

For the various sources of data the Weibull probability function was utilized to approximate the probability of the occurrence of wind speeds. The Weibull distribution [8] is

$$
\begin{aligned}
P(v) & =\frac{K}{c}\left(\frac{v}{c}\right)^{k-1} e^{-(v / c)^{k}} & & v>0, \\
& =0, & v & \leq 0 .
\end{aligned}
$$

This distribution is given by (1) where $k$ is the shape parameter and $c$ the scale parameter.

Wind power density, expressed in watt per square meter $\left(\mathrm{W} / \mathrm{m}^{2}\right)$, takes into account the frequency distribution of the wind speed and the dependence of wind power on air density and the cube of the wind speed. Therefore, wind power density is generally considered as a better indicator of the wind resource than wind speed. The mean wind power density available over a period $T$ is given by (2). In this equation, $\rho$ is the air density and $\bar{E}$ is given in $\left(\mathrm{W} \cdot \mathrm{m}^{-2}\right)$ :

$$
\bar{E}=\frac{1}{2} \frac{1}{T} \int_{0}^{T} \rho v^{3}(t) d t
$$

$\rho$ may be taken as a constant with an error of a few percent [9]. It should be noted that the velocity expression of (2) is based on values of average speed not instantaneous values. Also sitting within dense vegetation such as a forest or an orchard require establishment of a new effective ground level at approximately the height where the branches of adjacent trees touch, below this Level there is a little wind. In a dense cornfield wind, this height would be the average corn height or average height of the tree canopy for a forest area. In areas of high wind, wind power can be quite reliable and inexpensive. However, for wind energy to be economically viable, it has to deliver to a wind turbine an average annual wind speed of at least $5.36 \mathrm{~ms}^{-1}$ and above [9].

In general, daily and seasonal changes as well as wind direction are important considerations while sitting wind systems. From five LGED stations, it was found that the average annual wind speed values at $10 \mathrm{~m}, 20 \mathrm{~m}, 30 \mathrm{~m}$ height for the five wind stations vary from $1.73 \mathrm{~m} / \mathrm{s}$ to

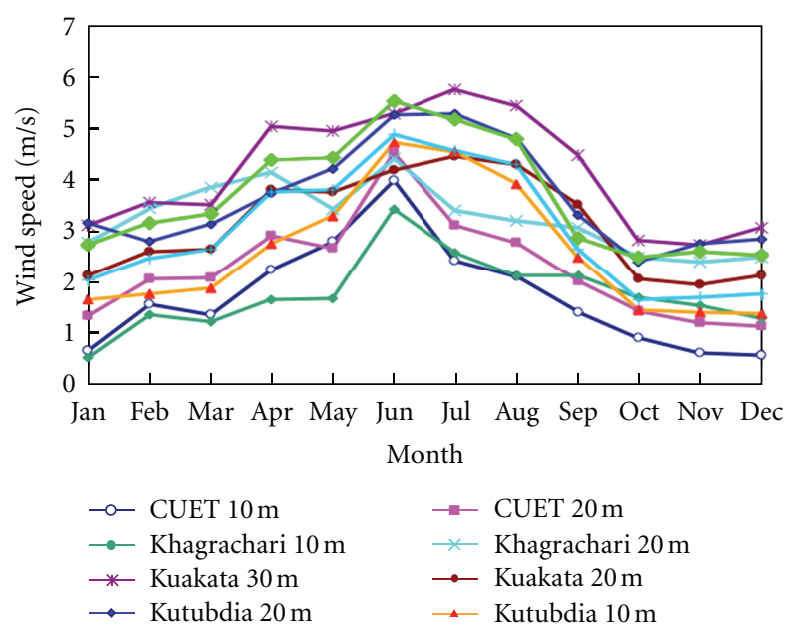

Figure 1: Monthly variation of wind speed for sites at different heights.

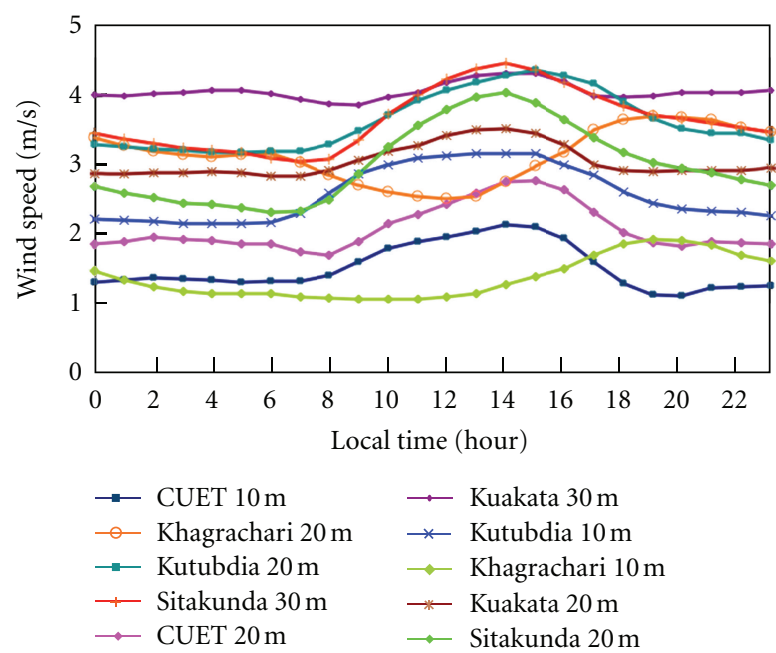

FIGURE 2: Diurnal variation of wind speed for sites at different heights.

$4.17 \mathrm{~m} / \mathrm{s}$. The highest average annual wind speed $(4.17 \mathrm{~m} / \mathrm{s})$ was observed in Kuakata and the lowest value $(1.32 \mathrm{~m} / \mathrm{s})$ was observed in Khagrachari. The analysis showed that highest wind speed was found during summer at Kutubdia and Kuakata. The annual cycle of monthly average wind speed shows fairly large seasonal variation, the appearance of which is typical for measurement sites, with minimum values in winter (October-March) and maximum values during summer (April-September, Figure 1). Similar variations also observed for BCAS Kutubdia and Kuakata stations [10, 11]. The analysis of the daily cycle of the wind speed at different time instants, however, suggests that the dominance of daytime winds over night winds that is characteristic of mainland measurement sites also contributes to this feature. The hourly variation of wind speed is shown in Figure 2. While there is almost no dependence of the wind speed on the measurement time for Kuakata and a weak maximum becomes evident at afternoon for all stations. 


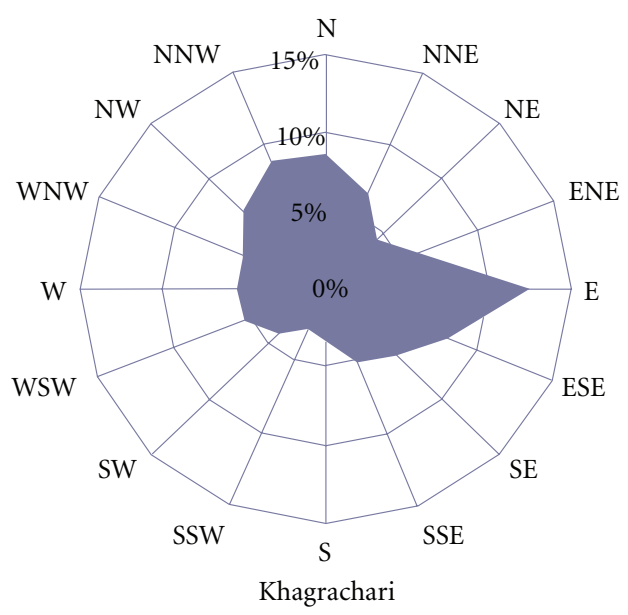

(a)

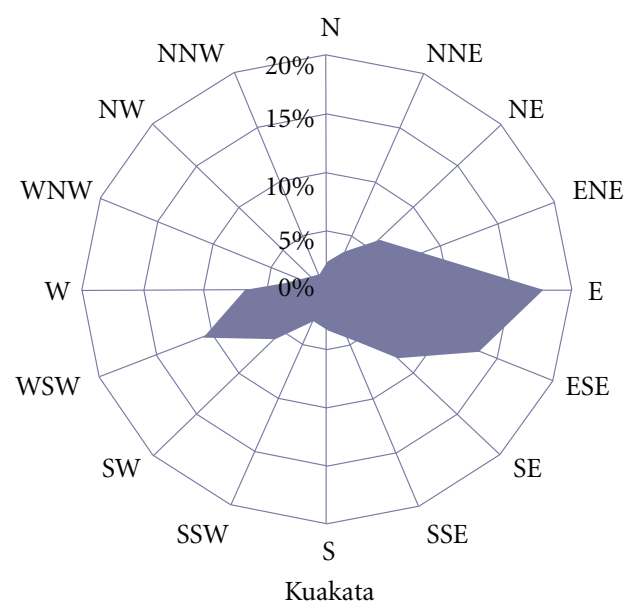

(c)

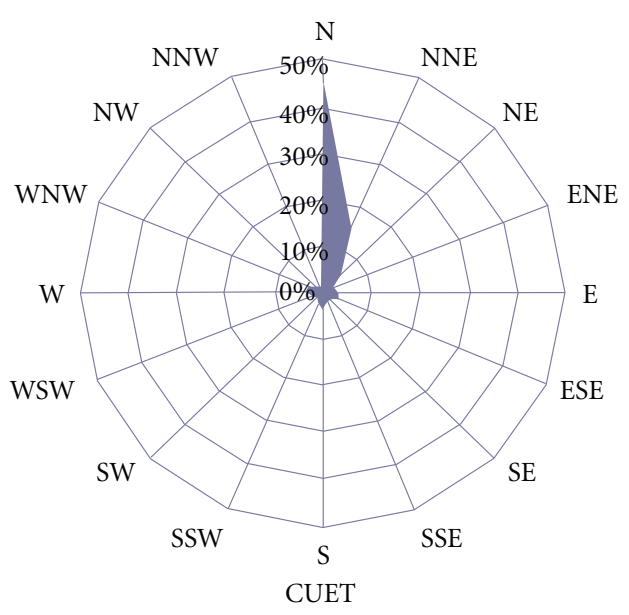

(b)

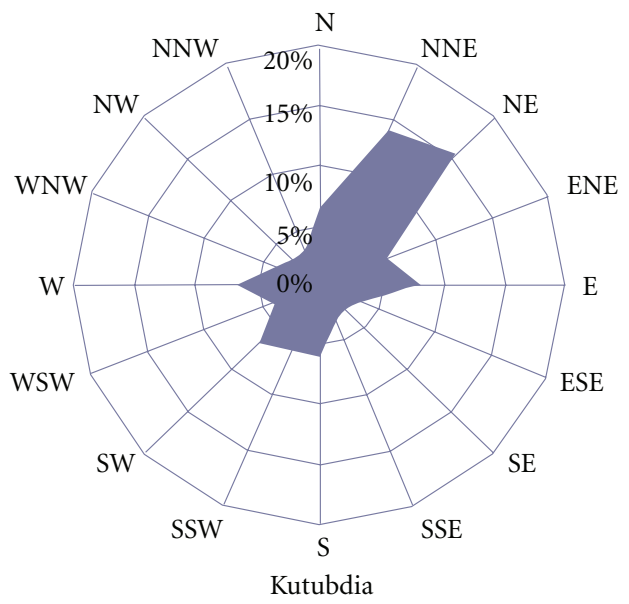

(d)

FIGURE 3: Wind rose for different locations showing percentage of wind direction.

Such a variation is similar to that observed for at BCAS wind monitoring station of Kutubdia and Kuakata wind measurement sites [10, 11]. A part of this cycle is obviously due to the local sea breeze. The typical spatial scale for changes of the diurnal cycle apparently depends on many factors such as the area covered by sea breeze, the geometry of the coastal region, or the mutual orientation of the land and sea, and the direction of air flow. From the above analysis it might be concluded that the daily cycle of wind speed should be taken into account when a wind farm is planned in the vicinity of a specific site.

A wind rose is the term given to the way in which the joint wind speed and direction distribution is defined. The wind speed data for LGED stations were grouped into twelve directional sectors: north-north west (NNW), north $(\mathrm{N})$, north-north east (NNE), eastnorth east (ENE), east (E), eastsouth east (ESE), southsouth east (SSE), south (S), southsouth west (SSW), westsouth west (WSW), west (W), and westnorth west (WNW). So, each one extended over $30^{\circ}$ according to the direction from which the wind blows. The design of a wind farm is sensitive to the shape of the wind rose for the site. In some areas, particularly in areas where the wind is driven by thermal effects, the wind can be very unidirectional. Wind roses providing the percentage of wind direction for different stations for the whole year have been constructed as shown in Figure 3. The coastal and mainland wind are less directionally homogeneous and only show a slight prevalence of north and southwest winds. The coastal winds are mostly driven by large-scale atmospheric dynamics and are less affected by local orography and obstacles where as the inland sites (CUET and Khagrachari) are strongly affected by orography and obstacles.

The Weibull parameters were calculated by least square method. It is found that the value of $k$ during summer for all stations is higher and that of winter is lower. A small value of $k$ indicates widely dispersed data, that is, the data tend to distribute uniformly over a relatively wide range of wind speed. If mean wind speed is low, this has a negative implication on wind power generation because the station does not experience enough wind speed to operate a wind turbine. For large values of $k$, the majority of wind speed data tend to fall around the mean wind speed, and if the mean wind speed is high, then the station experiences enough wind speed to operate a wind turbine at least for a short period 


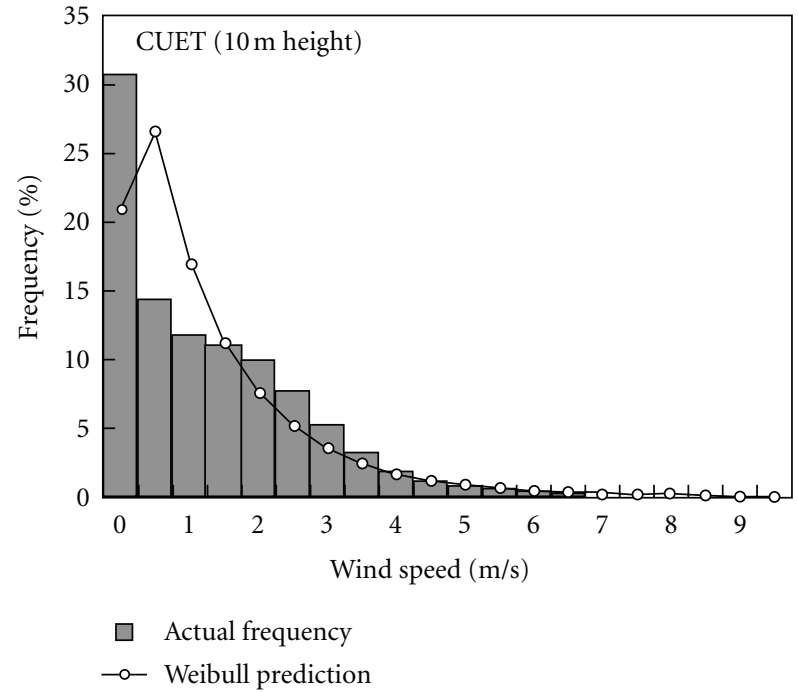

(a)

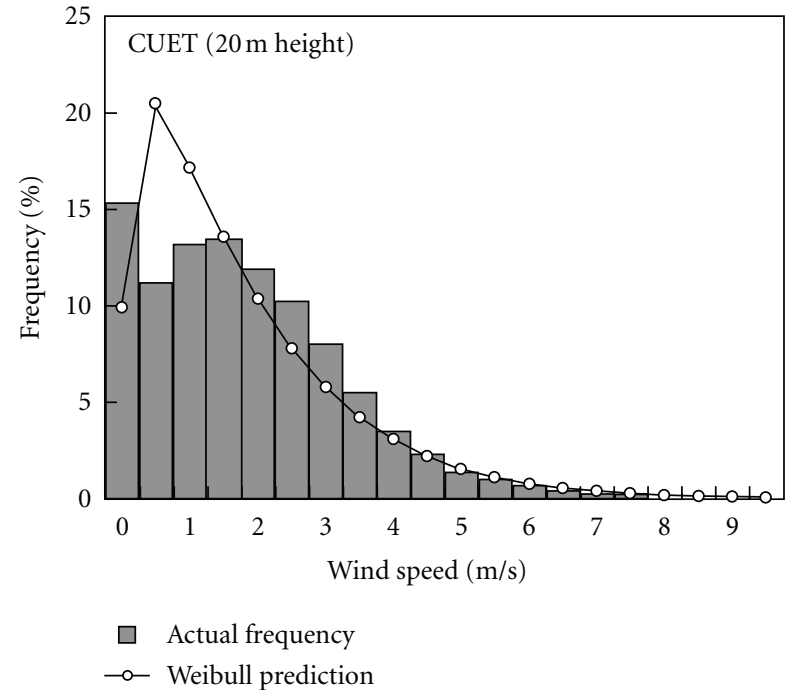

(b)

FIGURE 4: Actual and predicted wind speed probability for CUET, for different heights.

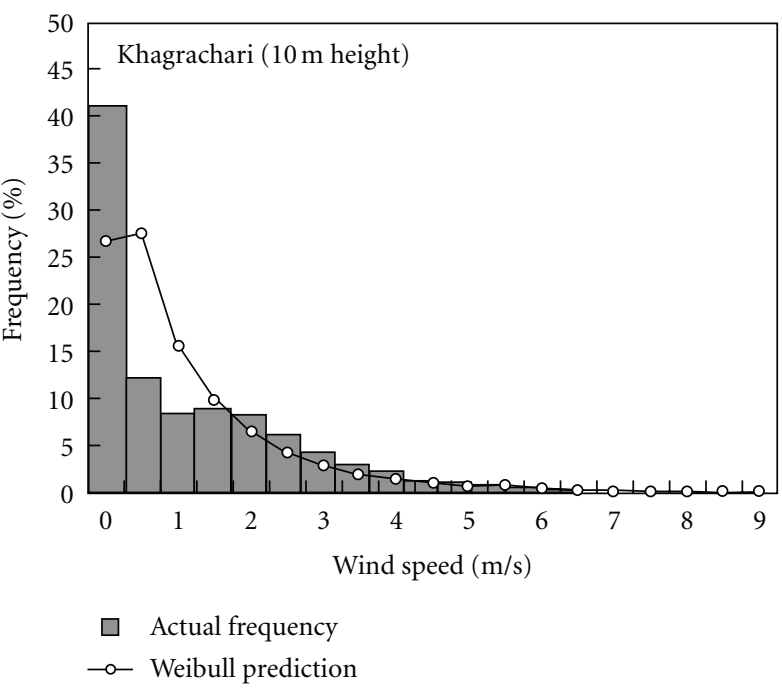

(a)

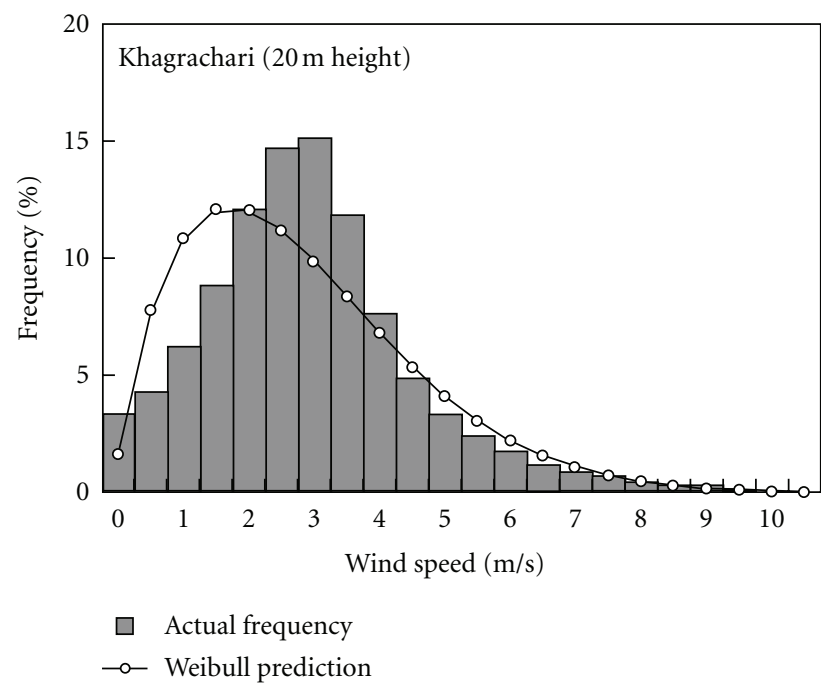

(b)

FIGURE 5: Actual and predicted wind speed probability for Khagrachari for different heights.

of time. The frequency distribution functions for different stations and heights are shown in Figures 4-8 enable one to estimate the probability of exceeding certain wind speed thresholds that could be important for wind farm planning.

Wind power density is considered to be the best indicator to determine the potential wind resource, which is critical to all aspects of wind energy exploitation, from the identification of suitable sites and predictions of the economic viability of wind farm projects through to the design of wind turbines themselves. Monthly and diurnal variation of wind power density is shown in Figures 9 and 10. The power density was calculated using (2). As wind power density depends on the cube of speed $\overline{v^{3}}$ the available wind energy is much higher during the windy months. During June and July wind power density is higher than other months. Maximum wind power density was in Kuakata $\left(88 \mathrm{~kW} / \mathrm{m}^{2}\right)$ at height $30 \mathrm{~m}$ and minimum in Khagrachari $\left(13 \mathrm{~kW} / \mathrm{m}^{2}\right)$ at a height $10 \mathrm{~m}$.

\section{Solar Radiation Assessment}

A study [5] showed that the cloud cover measurements are satisfactory in all the BMD stations. Variation of sunshine duration and cloud cover with years are shown in the Figures 11 and 12 .

According to the method suggested by Rangarajan et al. [12], the relation between the relative sunshine duration and state of the sky is

$$
\frac{n}{N^{\prime}}=\frac{a n_{1}+b n_{2}+c n_{3}}{n_{123}},
$$




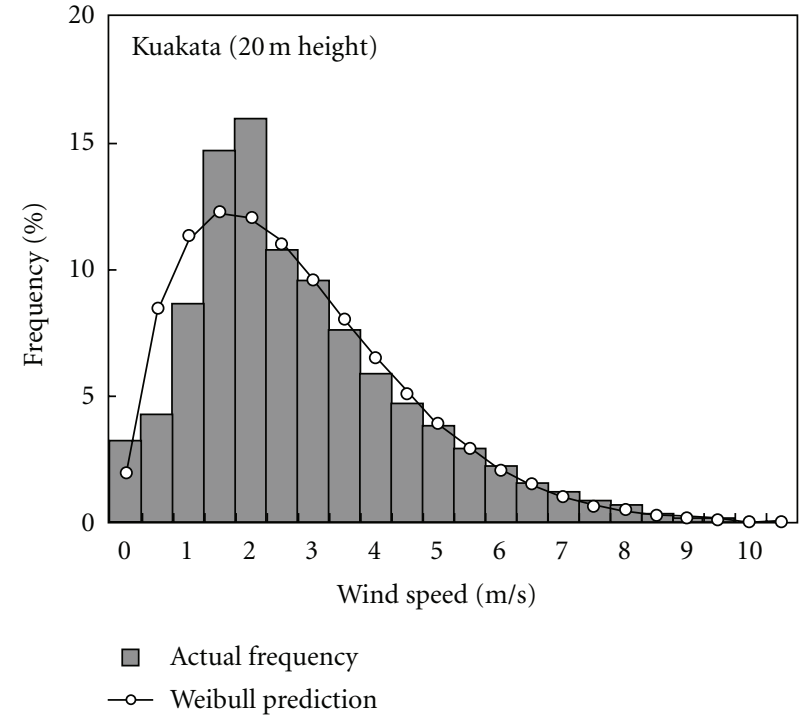

(a)

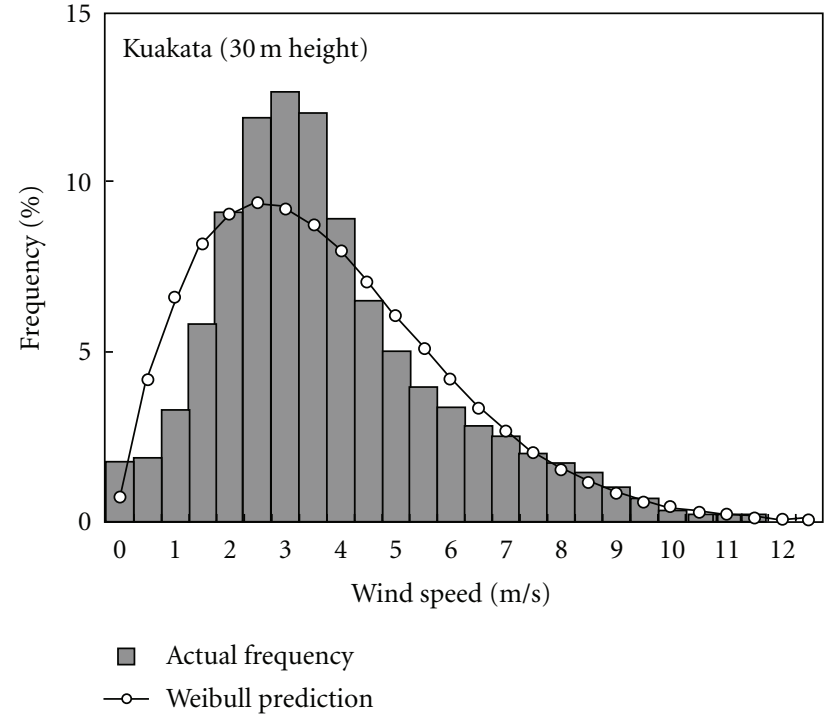

(b)

FIGURE 6: Actual and predicted wind speed probability for Kuakata for different heights.

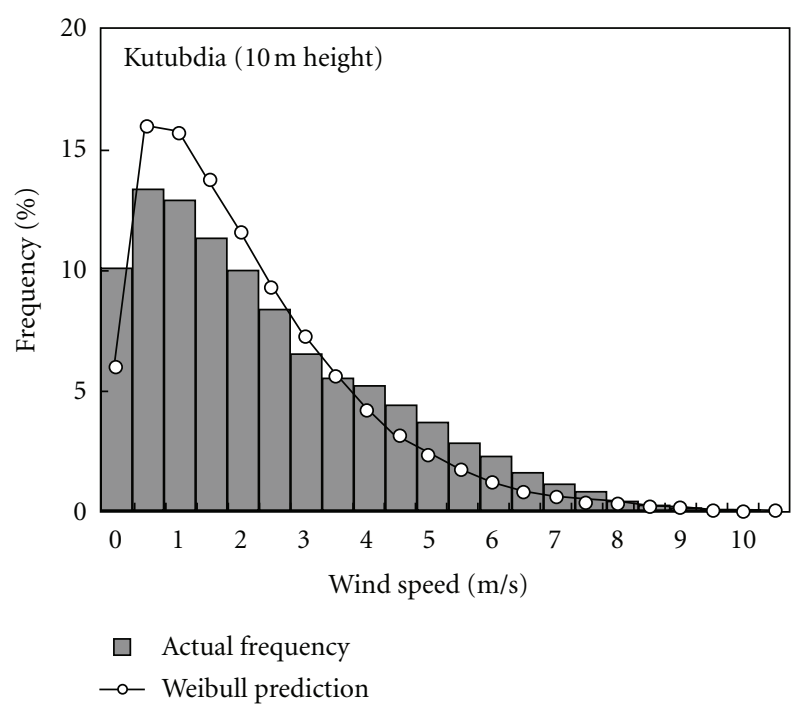

(a)

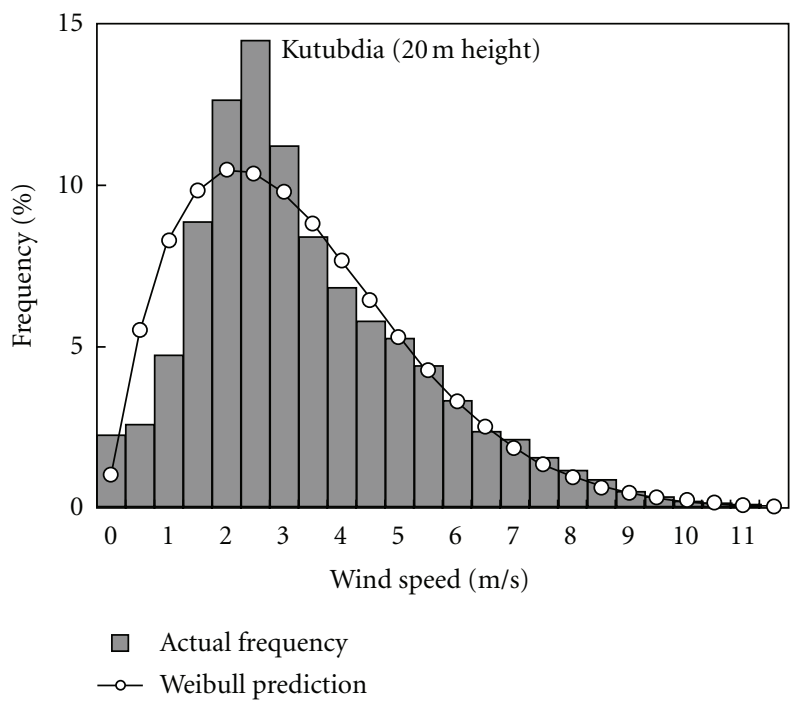

(b)

FIGURE 7: Actual and predicted wind speed probability for, Kutubdia for different heights.

where $n_{1}$ is the number of clear days, $n_{2}$ is the number of mixed days, $n_{3}$ is the number of overcast days in a month, $n_{123}=n_{1}+n_{2}+n_{3}$ is the total number of days in the month under consideration, and $a, b, c$ are climatological parameters. $N^{\prime}$ is the period when the Campbell-Stokes sunshine recorder remains sensitive over the representative day for the month and

$$
N^{\prime}=\frac{\arccos ((\cos 85-\sin \phi \sin \delta) / \cos \phi \cos \delta)}{7.5},
$$

$\phi$ is the latitude of the station and $\delta$ is the declination [13]. Generally to estimate the monthly averaged daily global radiation on a horizontal surface a simple and well-known model is Angstrom equation modified by Page [14]:

$$
\frac{\bar{H}}{\bar{H}_{0}}=a+b \frac{\bar{n}}{\bar{N}}
$$

$\bar{H} / \bar{H}_{0}$ is the ratio of monthly averaged daily global to monthly averaged daily extraterrestrial radiation on a horizontal surface [14]. This ratio is known as clearness index $\bar{K}_{T}$, gives the percentage deflection by the sky of the incoming global radiation, and therefore indicates both the level of availability of solar radiation and changes in atmospheric conditions in a given locality while relative sunshine duration, $\bar{n} / \bar{N}$ is a measure of the cloud cover. Here, 


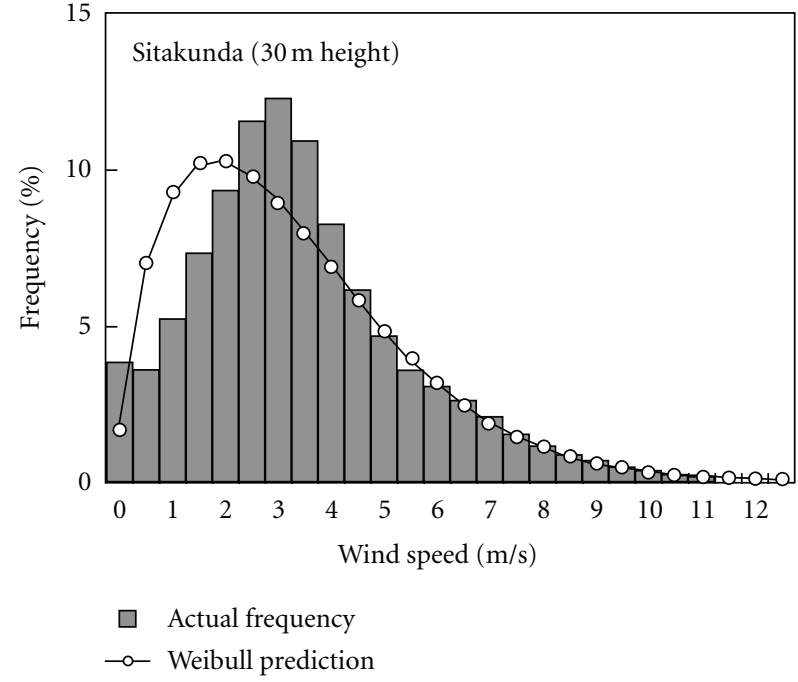

(a)

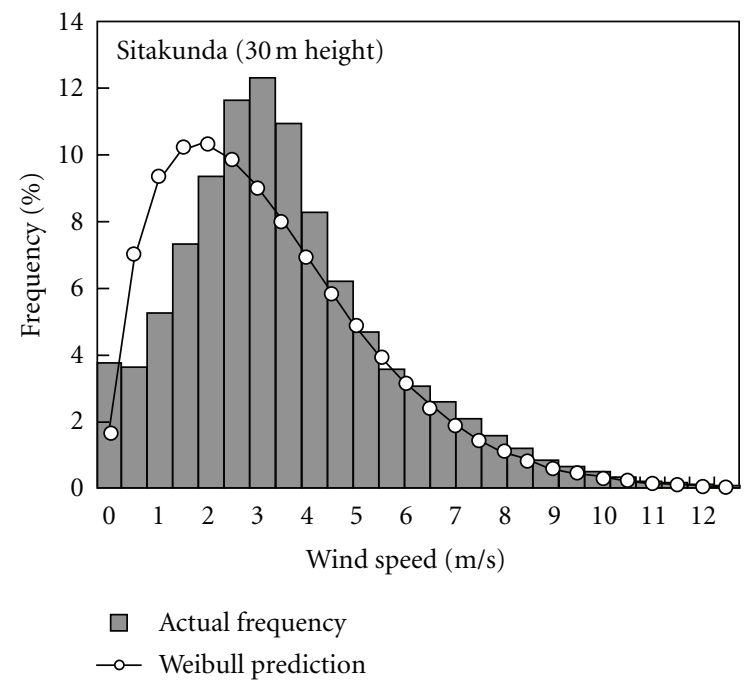

(b)

FIgURE 8: Actual and predicted wind speed probability for Sitakunda for different heights.

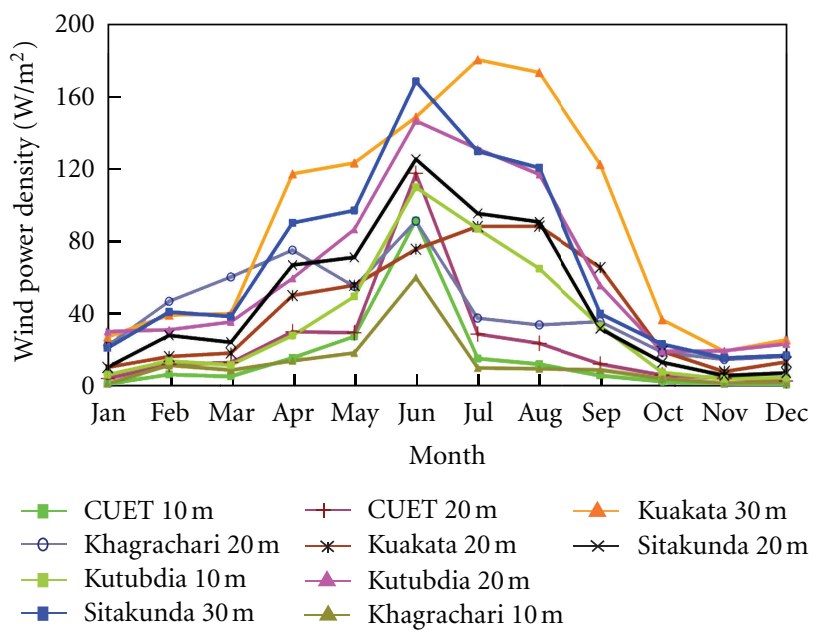

FIGURE 9: Monthly variation of wind power density for different station and heights.

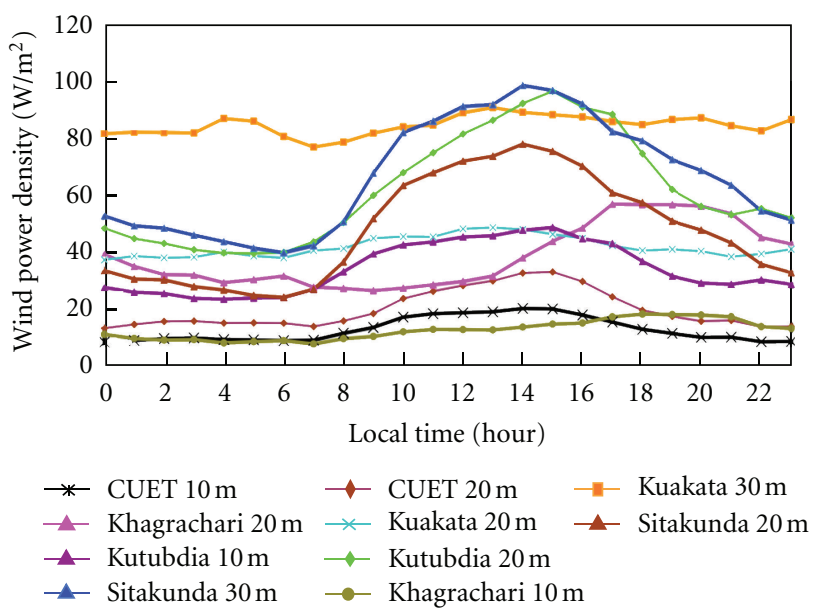

FIGURE 10: Hourly variation of wind power density for different station and heights. $a$ and $b$ are regression coefficients. $H_{0}$ and $N$ were evaluated according to equations reported in Iqbal [15] for sunshine duration and global radiation relation. The parameters of (5) have been chosen from a recent work of Hussain et al. [16].

In this study, three methods are used to evaluate the accuracy of the correlations described above. The root mean square error is defined as

$$
\operatorname{RMSE}=\left\{\frac{\left[\sum \overline{\mathrm{H}}_{\text {dical }}-\overline{\mathrm{H}}_{\text {dim eas }}\right]^{2}}{n}\right\}^{1 / 2},
$$

where $\bar{H}_{\text {dical }}$ is the $i$ th calculated value, $\bar{H}_{\text {dimeas }}$ is the measured value and $n$ is the total number of observations. The mean bias error is defined as

$$
\mathrm{MBE}=\frac{\left[\sum\left(\bar{H}_{\text {dical }}-\bar{H}_{\text {dimeas }}\right)\right]}{n} .
$$

The mean relative percentage error is defined as

$$
\mathrm{MPE}=\frac{\left[\sum\left(\left(\bar{H}_{\text {dim eas }}-\bar{H}_{\text {dical }}\right) / \bar{H}_{\text {dim eas }}\right) \times 100\right]}{n} .
$$

In the third method, the sign of the errors is neglected in the summation and all the percentage errors are added up while calculating the mean. The errors for the hourly global radiation prediction methods are calculated using equations $((6)-(8))$ and given in Table 2. The RMSE and MBE are in $\mathrm{W} / \mathrm{m}^{2}$.

\section{Technoeconomical Study of Grid-Connected Wind and PV Systems}

As some of the coastal inland parts may be viable for wind energy generation and some of the northern parts are best 


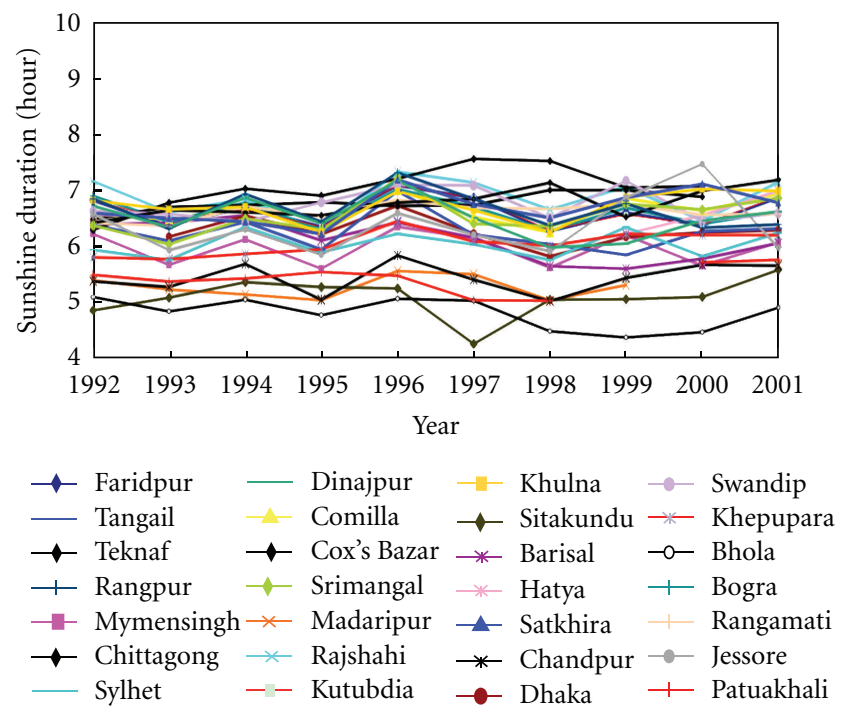

FIgURE 11: The variation of the yearly averaged daily sunshine duration over different stations.

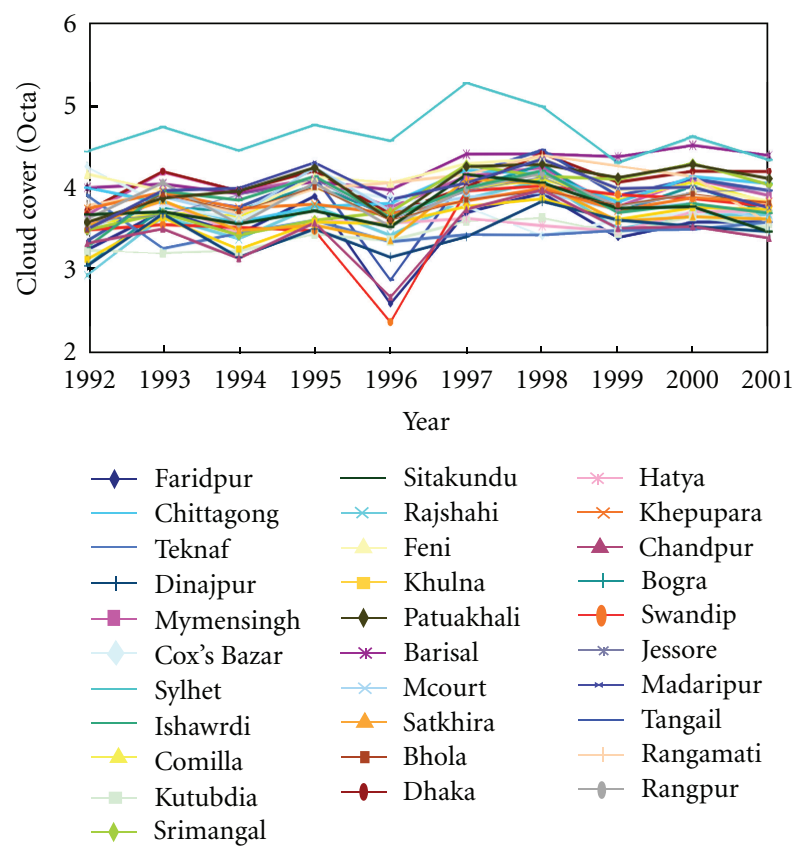

FIGURE 12: The variation of the yearly averaged daily cloud cover data over different stations.

TABLE 2: MBE, RMSE, and MPE for global and diffuse radiation correlations.

\begin{tabular}{lcc}
\hline MBE & RMSE & MPE \\
\hline 9.246 & 32.92 & 14.72 \\
\hline
\end{tabular}

for solar energy, therefore renewable-based grid-connected system for both of the locations have been analyzed. It has been found in the WAsP analysis and resource map developed by RISOE that some of the coastal inland parts may be suitable for small wind energy generation where wind
TABLE 3: Output of RETScreen for a $100 \mathrm{~kW}$ grid-connected wind energy system, where wind power density is around $200 \mathrm{~W} / \mathrm{m}^{2}$.

\begin{tabular}{lcc}
\hline Parameter & Unit & Value \\
\hline Annual wind power density & $\mathrm{W} / \mathrm{m}^{2}$ & 200 \\
Height o f wind power density & $\mathrm{M}$ & 50 \\
Wind plant capacity & $\mathrm{kW}$ & 100 \\
Gross energy production & $\mathrm{MWh}$ & 169 \\
Wind plant capacity factor & $\%$ & 17 \\
Renewable energy delivered & $\mathrm{tCO}_{2} / \mathrm{yr}$ & 153 \\
(Annually) & & \\
Net GHG reduction (Base & $\mathrm{tCO}_{2} / \mathrm{yr}$ & 171 \\
case-Diesel) & $\mathrm{BDT}^{\text {Initial cost }}$ & $18,637,500$ \\
Energy production cost & $\mathrm{BDT}^{\mathrm{k}} \mathrm{kWh}$ & 5.14 \\
\hline
\end{tabular}

TABLE 4: $100 \mathrm{~kW}$ grid-connected solar energy system.

\begin{tabular}{lcc}
\hline Parameter & Unit & Value \\
\hline PV energy absorption rate & $\%$ & 100 \\
Overall PV system efficiency & $\%$ & 12.3 \\
PV system capacity factor & $\%$ & 6.8 \\
Renewable energy collected & $\mathrm{MWh}$ & 156.29 \\
Renewable energy delivered & $\mathrm{MWh}$ & 148.47 \\
PV array area & $\mathrm{m}^{2}$ & 704.9 \\
Initial cost & $\mathrm{BDT}$ & $33,793,648$ \\
Energy Production cost & $\mathrm{BDT}^{2} \mathrm{kWh}$ & 09.68 \\
Net GHG reduction (base & $\mathrm{tCO}_{2} / \mathrm{yr}$ & 164.84 \\
case-diesel) & & \\
\hline
\end{tabular}

power density is around $200 \mathrm{~W} / \mathrm{m}^{2}$ [4]. Therefore, an analysis has been done for a grid-connected wind energy system. Table 3 outputs RET Screen for a $100 \mathrm{~kW}$ grid-connected wind energy system where wind power density is around $200 \mathrm{~W} / \mathrm{m}^{2}$. Energy production cost in Table 3 indicates that there should not be any doubt to connect the wind energy system to the national grid in Bangladesh. Figure 14 depicts that cost of energy (COE) of a grid-connected wind system increases with decrease in wind power density. The location with a wind power density $150 \mathrm{~W} / \mathrm{m}^{2}$ and above is economical feasible and such a system can be implemented.

A $100 \mathrm{~kW}$ grid connected solar energy system is depicted in Table 4. The solar modules were placed at south facing with azimuth angle of $0^{\circ}$. The solar modules are placed at the south facing with $0^{\circ}$ angle of azimuth. The modules are faced with an angle of $25^{\circ}$, same as the latitude angle of the site. For this study, solar panel model mono-Si-BP4175, capacity per unit $175 \mathrm{~W}$, and efficiency $12.39 \%$. The optimum sizes of the technologies that meet the maximum grid demand of $100 \mathrm{~kW}$ for the selected site under the given condition of solar resources are simulated by RETScreen. Maximum energy generated in April is 21.4 MWh and minimum energy generated in September is 11.32 MWh and annual total production is $148.475 \mathrm{MWh}$. Per unit energy production cost found for the proposed project is $9.68 \mathrm{BDT}$, which is competitive with diesel-based grid power generation. 


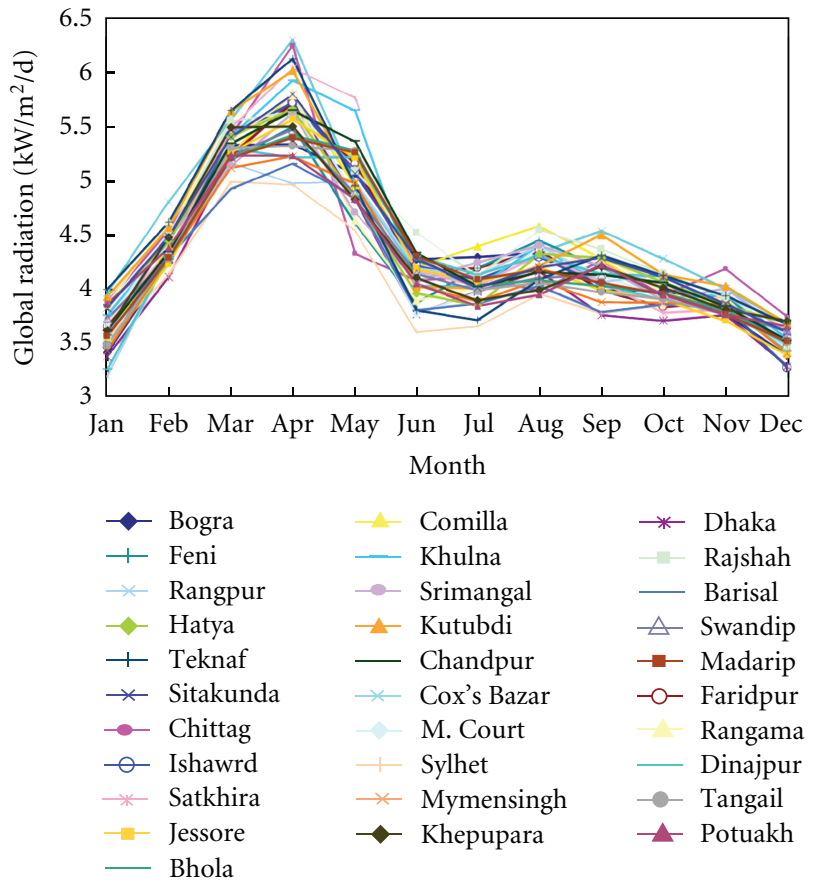

FIgURE 13: Global solar radiation over different stations of Bangladesh.

By using average monthly highest and lowest solar radiation at different parts of the country with same parameters, the production cost per unit of electricity is found to be 4.24 BDT to 21.05 BDT as shown in Figure 13. Sensitivity analysis results due to change of PV cost and discount rate are shown in Figures 15 and 16 respectively. It is found that per unit electricity production cost 4.24 BDT and 14.00 BDT when the PV panel costs are $100 \mathrm{BDT} / \mathrm{Wp}$ and $350 \mathrm{BDT} / \mathrm{Wp}$, respectively. Higher discount rate increases the electricity production cost. It is found that the electricity production cost is $9.00 \mathrm{BDT}$ when the discount rate is $6 \%$ and the cost reaches to around 20.05 BDT when the discount rate is $16 \%$. PV grid electricity generation system could be effective to extend the grid connection and available power for all. This study examines the feasibility of PV grid system for $100 \mathrm{~kW}$ generation plant. It is found that the per unit electricity production cost from the studied system is costcompetitive with grid-connected diesel power generation which is around 15-18 BDT [17].

\section{Conclusions}

The study reveals that Kutubdia and Kuakata have potential for wind power and consistent with other study such as BCAS measurement sites. We have used short-term data for the analysis. There is a general claim that minimum ten years data are required for proper assessment of wind resource at a particular site. It is required to measure wind speed for different heights and terrain effect to find out exact potential of each sites. At the end, the present work is only a preliminary study in order to assess wind energy analysis of the selected sites and give useful insights to engineers and

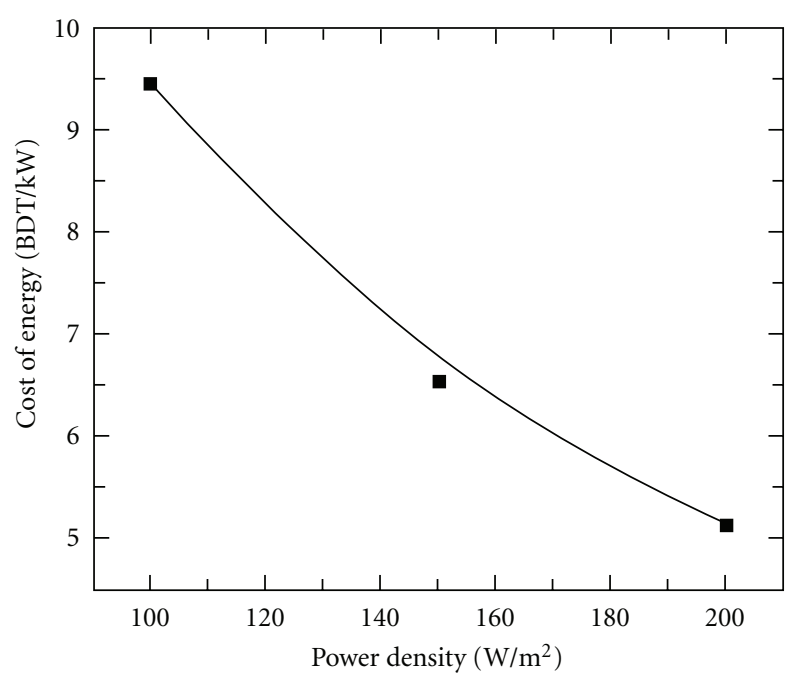

Figure 14: Product ion cost of energy at different power density in the coastal part of Bangladesh.

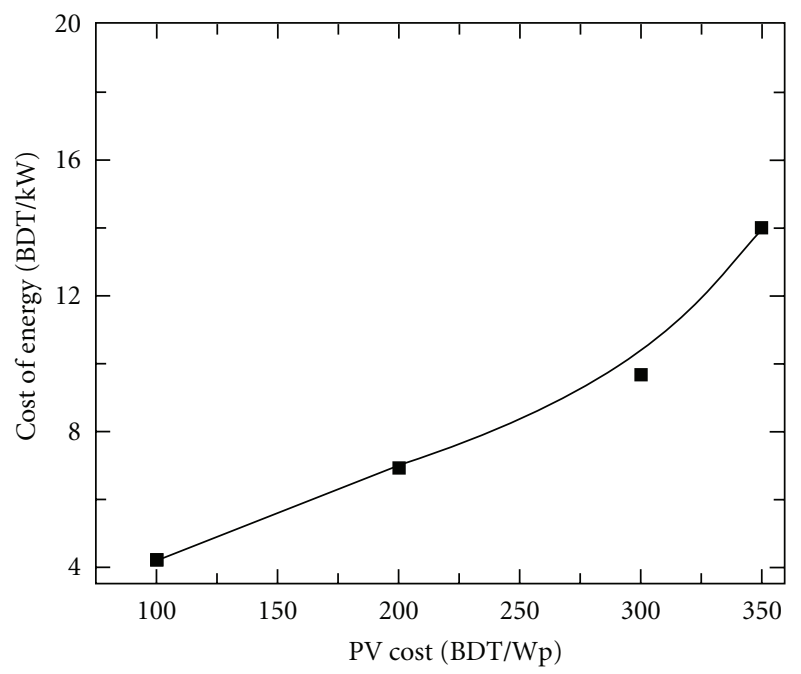

FIGURE 15: Sensitivity analysis due to the change of PV cost for the grid-connected system.

experts dealing with wind energy. In Bangladesh, generally a number of foggy days can be seen in January. For this reason we have correlated meteorological parameters for 11 months (except January). For estimation of sunshine duration we have calculated the ratios of measured and estimated values for satisfactory stations and considered that as fog factor (value $0.85-1.00$ ) for this month. The monthly averaged daily global radiation varies from $3.2 \mathrm{~W} / \mathrm{m}^{2} /$ day to $6.1 \mathrm{~kW} / \mathrm{m}^{2} /$ day. The variations of global solar radiation in Bangladesh can be divided into two groups-the low irradiation values being associated with high cloud while the high values are associated with low cloud cover. The high values of global solar radiation were observed during summer while low radiation was observed during winter.

Grouping the meteorological stations according to their position above or below $23.5^{\circ}$, previously, a work [18] had been done to predict sunshine duration from cloud cover. 


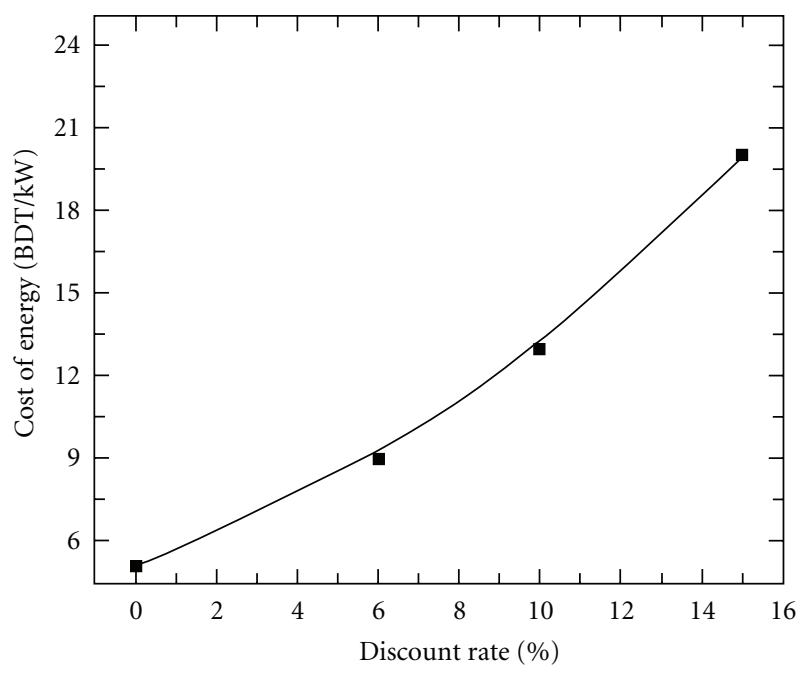

FIGURE 16: Sensitivity analysis due to the change of discount rate for the grid-connected system.

That method had standard deviation of $\mathrm{n} 0.45$ hours. To get sunshine duration from rainfall data, the previous work [18] had been done grouping rainfall stations according to different rainfall range. That technique had an average standard error 0.44 hours. This present work has an average standard deviation of 0.46 hours, which is almost the same as the previous work [5]. From the economic analysis results, it can be observed that the grid connected wind/PV system installed in Bangladesh provides the best case even excluding the addition of environmental externalities. In terms of environmental impacts, PV does not produce any pollution. The analysis shows that power systems using renewable energy sources can be economically attractive, particularly when environmental benefits are used in the calculation. Environmental benefits may include human health improvement, air pollution decrease, noise reduction, and so forth.

\section{Acknowledgments}

The authors must thank Sustainable Rural Energy (SRE) of Local Government engineering department (LGED) and Bangladesh Meteorological Department (BMD) for providing data for the study.

\section{References}

[1] Key world statistics, The International Energy Agency (IEA), 2010.

[2] Bangladesh Power Development Board (BPDB), http://www .bpdb.gov.bd/generation.htm.

[3] Final Report of Solar and Wind Energy Resource AssessmentBangladesh, Dhaka, Bangladesh, 2007.

[4] I. Troen and E. L. Petersen, European Wind Atlas, Risoe National Laboratory, Roskilde, Denmark, 1989.

[5] S. Barbaro, G. Cannata, S. Coppolino, C. Leone, and E. Sinagra, "Correlation between relative sunshine and state of the sky," Solar Energy, vol. 26, no. 6, pp. 537-550, 1981.
[6] Renewable Energy Technologies screen (RETScreen), http:// www.retscreen.net.

[7] W. Weibull, "A statistical distribution of wide applicability," Journal of Applied Mechanics, vol. 18, pp. 293-297, 1957.

[8] IEC, Iowa Wind Energy Data, Iowa Energy Centre Publications, USA.

[9] S. K. Khadem, S. M. Ullah, S. K. Aditya et al., "Wind resource assessment over Kutubdia Island," in Proceedings of the ISEA Asia-Pacific, pp. 454-460, Bangladesh, Dhaka, 2004.

[10] S. K. Nandi and H. R. Ghosh, "Techno-economical analysis of off-grid hybrid systems at Kutubdia Island, Bangladesh," Energy Policy, vol. 38, no. 2, pp. 976-980, 2010.

[11] H. R. Ghosh, S. M. Ullah, S. K. Khadem et al., "Estimation of sunshine duration from cloud cover data for Bangladesh," University Journal for Science, vol. 54, no. 2, pp. 187-190, 2006.

[12] S. Rangarajan, M. S. Swaminathan, and A. Mani, "Computation of solar radiation from observations of cloud cover," Solar Energy, vol. 32, no. 4, pp. 553-556, 1984.

[13] A. Angstrom, "Solar and terrestrial radiation," Quarterly Journal of the Royal Meteorological Society, vol. 50, pp. 121125, 1924.

[14] J. K. Page, "The estimation of monthly mean values of daily total short wave radiaton on vertical and inclined surfaces from sunshine records for latitudes $40^{\circ} \mathrm{N}-40^{\circ} \mathrm{S}$," in Proceedings of the United Nations Conference on New Sources of Energy, vol. 4, pp. 378-390, 1961.

[15] H. R. Ghosh, L. Mariam, S. K. Khadem et al., "Estimation of monthly averaged daily and global and diffuse radiation for Bangladesh," Dhaka University Journal of Science, vol. 4, no. 1, pp. 109-113, 2006.

[16] M. Hussain, "Solar radiation over Bangladesh," in Proceedings of the Regional workshop on Rural Electrification through Solar Photovoltaic and Rural Energy planning with Renewables, Dhaka, Bangladesh, 1996.

[17] The New Nation, "Gas Crisis: 4 power plants likely to use liquid fuel from August,", 2009.

[18] H. R. Ghosh, S. M. Ullah, S. K. Khadem et al., "Estimation of sunshine duration from cloud cover data for Bangladesh," in Proceedings of the International Conference on Renewable Energy Technology for Rural Development, pp. 315-318, Kathmandu, Nepal, 2003. 

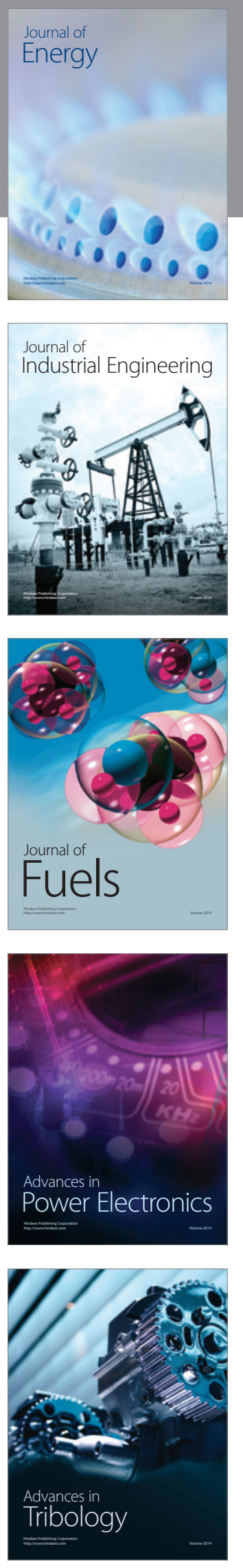
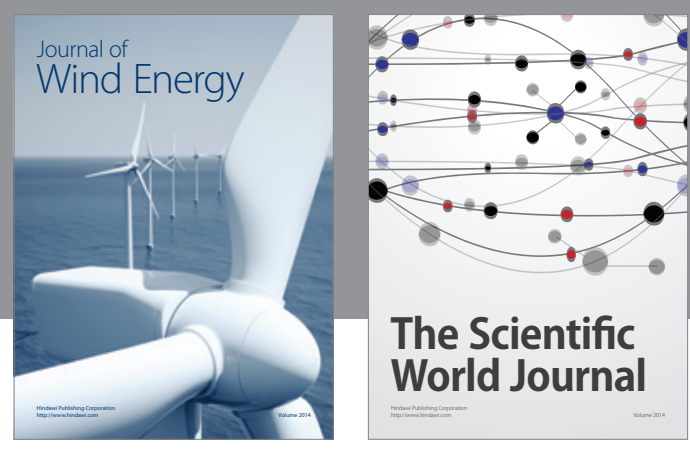

The Scientific World Journal

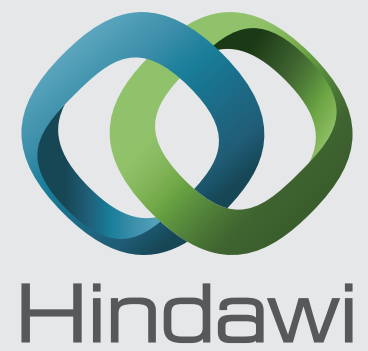

Submit your manuscripts at http://www.hindawi.com
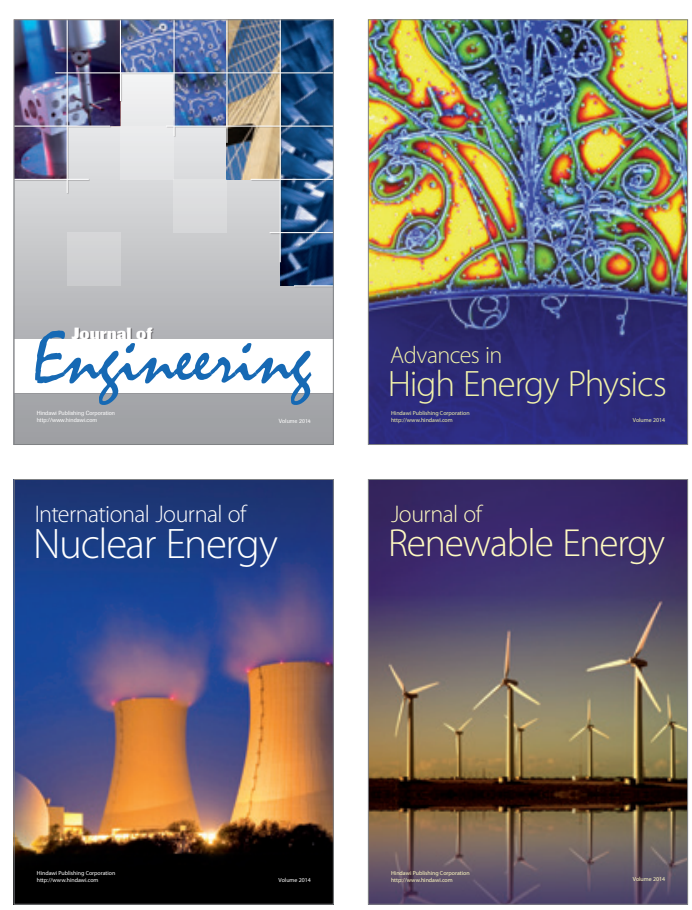

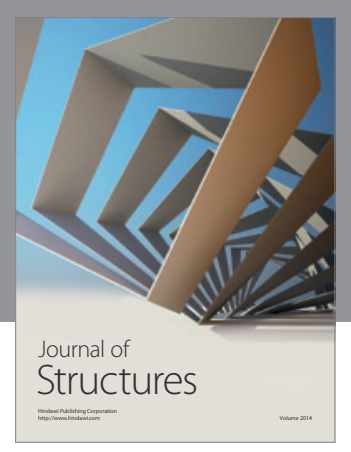

Rotating
Mechinery
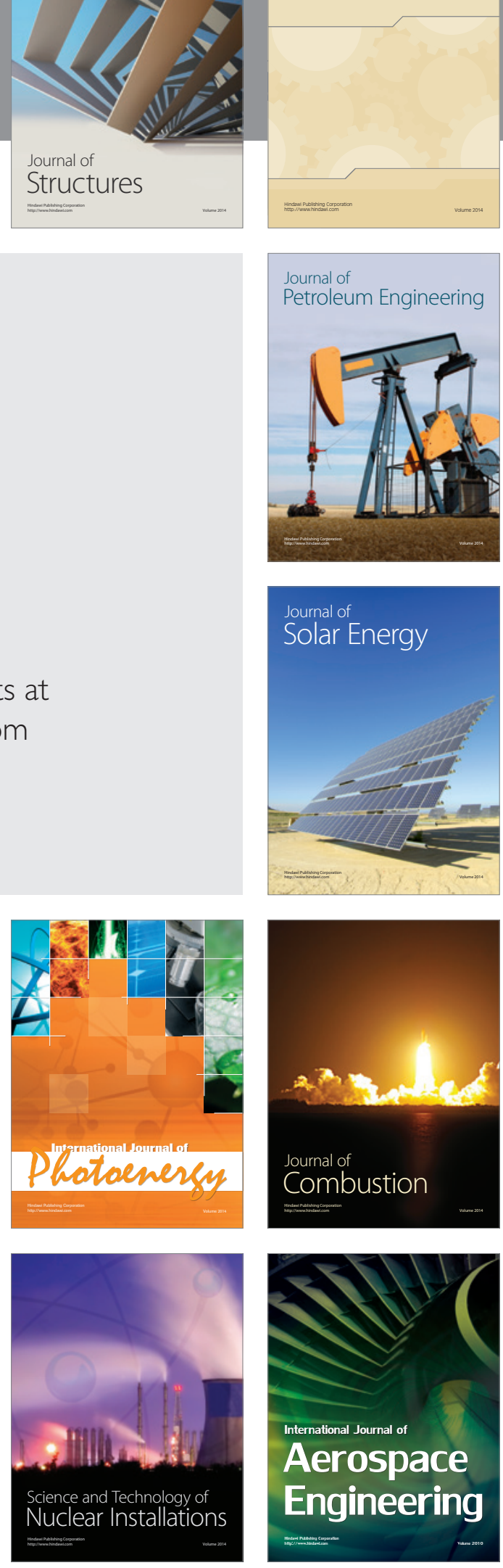